07

\title{
Наносекундная динамика разрушения гетерогенного твердого тела (гранита) при ударе по его поверхности
}

\author{
(С) В.И. Веттегрень, И.П. Щербаков, Р.И. Мамалимов \\ Физико-технический институт им. А.Ф. Иоффре РАН, \\ Санкт-Петербург, Россия \\ E-mail: Victor.Vettegren@mail.ioffe.ru
}

(Поступила в Редакцию 26 апреля 2016 г.)

\begin{abstract}
С временны́м разрешением $2 \mathrm{~ns}$ проведены исследования динамики образования микротрещин и деформации поверхности образца гранита под влиянием удара бойком по его поверхности. Удар вызывает появление собственных колебаний образца, которые приводят к образованию кластеров из микротрещин с линейными размерами от $\sim 2$ до $\sim 10 \mu \mathrm{m}$ в зернах полевого шпата. Образование микротрещин в свою очередь вызывает появление собственных колебаний зерен.
\end{abstract}

Работа выполнена при финансовой поддержке РФФИ (грант № 16-05-00138 а).

\section{1. Введение}

Метод фрактолюминесценции (FL), позволяющий исследовать образование возбужденных свободных радикалов и ионов при разрыве химических связей, используется для изучения механизма разрушения кварца и гранитов уже более 30 лет [1-10]. Ранее в спектрах FL гранитов при их разрушении наблюдалась полоса $1.9 \mathrm{eV}$, соответствующая возбужденным свободным радикалам $\mathrm{SiO}^{*}$ [8-10]. Радикалы образуются при разрыве связей $\mathrm{Si}-\mathrm{O}-\mathrm{Si}$ в кристаллических решетках кварца и полевых шпатов, входящих в состав гранитов.

В работах [6-10] были проведены исследования временны́х зависимостей интенсивности FL (с временны́м разрешением $10 \mathrm{~ns}$ ), возникающей при ударе бойком по образцам кварца и гранитов. Оказалось, что она имеет вид отдельных вспышек длительностью $\sim 30$ ns. Было сделано предположение, что каждая из таких вспышек соответствует рождению микротрещины. По интенсивности вспышек и скорости распространения упругих волн оценен средний размер микротрещин. Как оказалось, он лежит в пределах от 8 до $40 \mu \mathrm{m}$ [7-10]. Микротрещины такого размера были действительно обнаружены на поверхности гранитов методом оптической микроскопии.

Однако из литературы [11] известно, что время жизни свободных радикалов обычно составляет несколько наносекунд. Поэтому часть из них успевала „погибнуть“ за время регистрации вспышек (10 ns), что могло повлиять на форму и интенсивность вспышек, а значит, привести к некорректной оценке размеров микротрещин. В настоящей работе описаны результаты исследований динамики FL и деформации образца с помощью новой установки, временно́е разрешение которой составляет 2 ns. Это позволило, как показано далее, обнаружить новые детали динамики образования микротрещин и деформации гранита при ударе по его поверхности.

\section{2. Методика эксперимента}

Для исследования был выбран образец гранита, содержащий $\sim 30$ vol.\% зерен кварца и $\sim 70$ vol.\% полевых шпатов. Образцы имели вид кубов с полированными гранями и размером ребер $\sim 11 \times 11 \times 11 \mathrm{~cm}$. Размеры зерен полевого шпата и кварца были измерены при помощи оптического микроскопа. Оказалось, что они составляют от 0.4 до $\sim 1.4 \mathrm{~mm}$.

Конструкция установки, использованной для исследования динамики FL и волн деформации при ударе, описана в [8]. В новой установке вместо аналоговоцифрового преобразователя ASK-3106 использовался преобразователь ADS-3112, что позволило изменить временно́е разрешение регистрирующей системы в 5 раз (с 10 до $2 \mathrm{~ns}$ ).

Волны деформации и FL возбуждались ударом груза массой $50 \mathrm{~g}$, падающего с высоты $\sim 10 \mathrm{~cm}$ на стальной боек. Боек представлял собой стальной стержень, вершина которого имела радиус закругления $\sim 1 \mathrm{~mm}$. Известно, что прочность зерен полевого шпата значительно меньше, чем кварца, и при ударе в них в первую очередь зарождаются микротрещины [7]. Поэтому боек устанавливался так, чтобы его вершина располагалась на одном из зерен полевого шпата. Возникающее излучение при помощи фокона фокусировалось на поверхность катода фотоэлектронного умножителя РEM-136. Для измерения профиля и скорости $S$ распространения механического импульса, вызванного ударом, на поверхность на расстоянии $5 \mathrm{~mm}$ от места расположения бойка устанавливалась квадратная пластина из пьезокерамики CTS-19. Длина ребер пластины составляла $4 \mathrm{~mm}$, а толщина $1 \mathrm{~mm}$. Величины напряжений на выходе PEM-136 и 
пьезокерамики после оцифровки записывалась в память компьютера.

\section{3. Динамика микротрещин после удара}

Временны́е зависимости интенсивности FL и деформации поверхности гранита показаны на рис. 1.

Как уже упоминалось, расстояние от места расположения вершины бойка до центра пластины из пьезокерамики CTS-19 составляет $5 \mathrm{~mm}$. Скорость пробега волны деформации в граните $S \approx 1 \mathrm{~km} / \mathrm{s}$ [8-10], и это расстояние она пробегает за $5 \mu \mathrm{s}$. Поэтому для удобства сравнения с временно́й зависимостью FL начало временно́й зависимости деформации на рис. 1 было смещено в сторону низких времен на $5 \mu \mathrm{s}$.

Первая вспышка FL появляется в момент времени $148.8 \mu \mathrm{s}$, вслед за ней наблюдаются еще две вспышки.

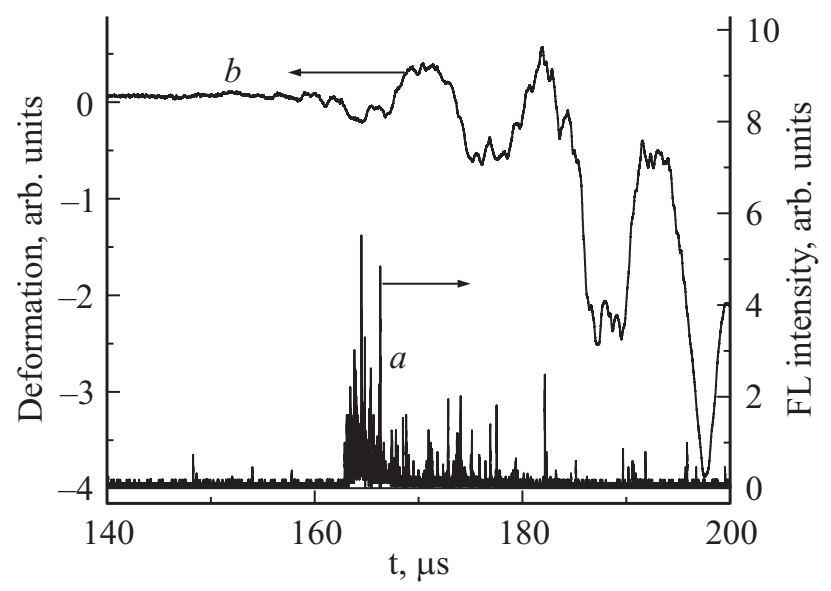

Рис. 1. Временны́е зависимости интенсивности FL $(a)$ и деформации поверхности $(b)$ образца гранита.

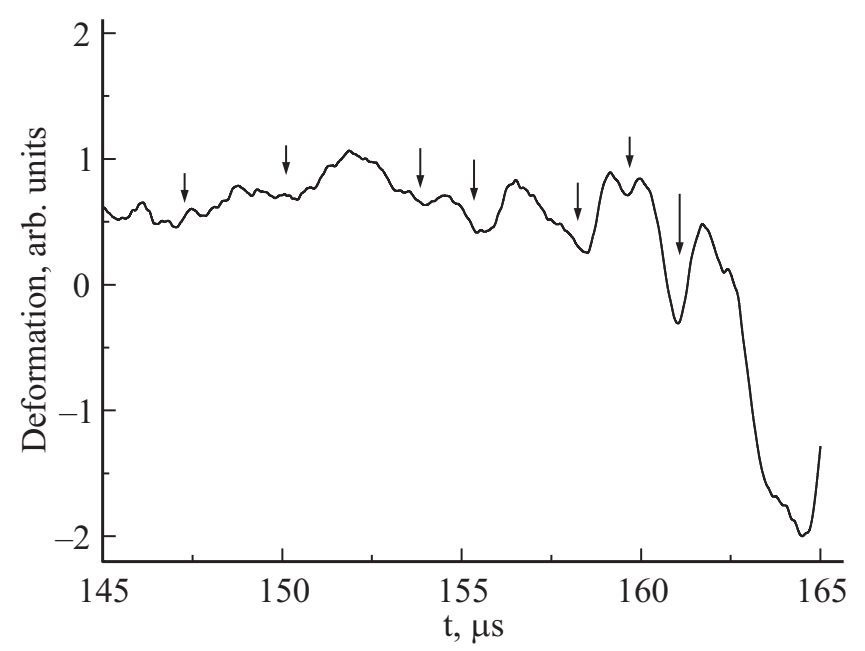

Рис. 2. Фрагмент временно́й зависимости деформации поверхности гранита. Стрелками показаны минимумы слабоинтенсивных волн деформации.
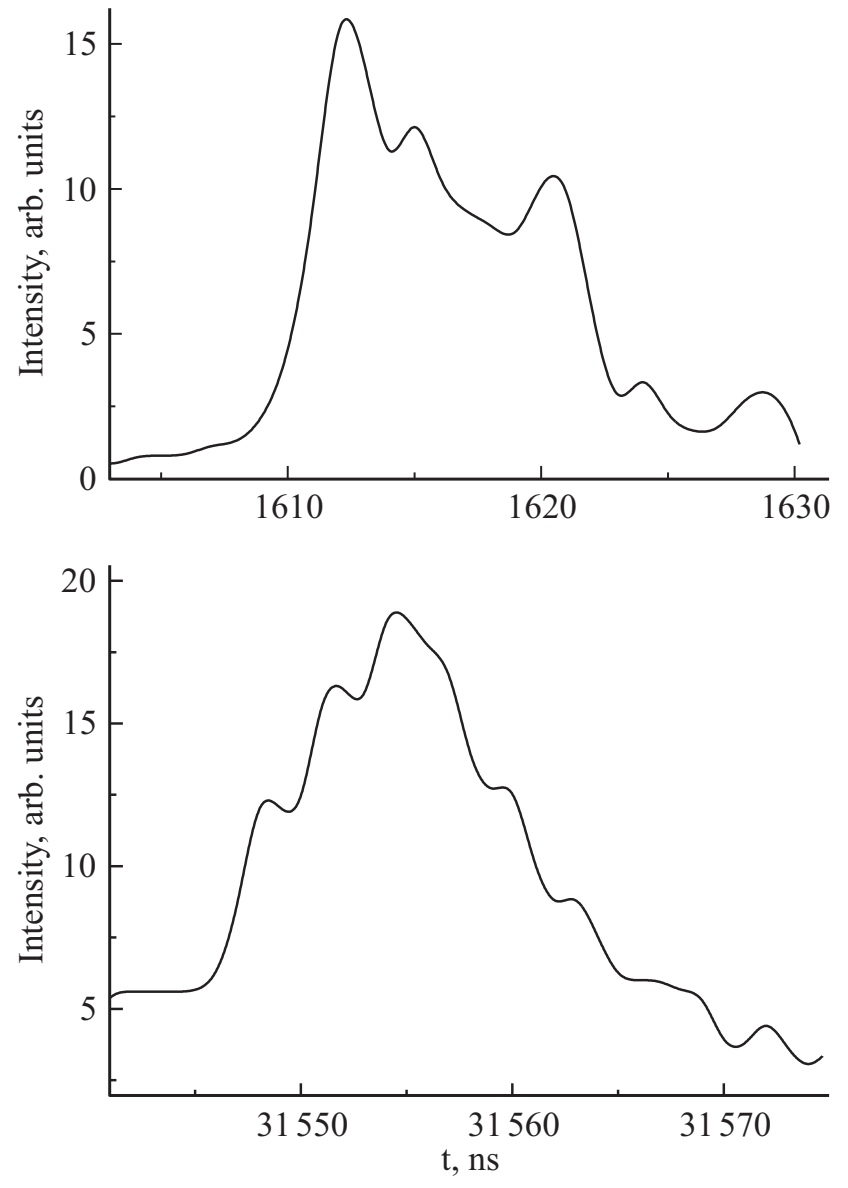

Рис. 3. Форма двух случайно выбранных вспышек.

В эти же моменты времени на временно́й зависимости деформации появляются слабоинтенсивные волны (рис. 2).

В момент времени $\sim 162.9 \mu \mathrm{s}$ образуется мощная волна деформации: поверхность образца начинает вспучиваться и растягиваться (кривая $b$ на рис. 1). Одновременно интенсивность и число вспышек резко увеличиваются. Как показано в $[8,10]$, FL возникает при релаксации электронного возбуждения свободных радикалов $\mathrm{SiO}^{*}$. Эти радикалы образуются после разрыва связей $\mathrm{Si}-\mathrm{O}-\mathrm{Si}$ в полевом шпате. По-видимому, именно вспучивание поверхности вызывает резкое увеличение числа разрывов связей $\mathrm{Si}-\mathrm{O}-\mathrm{Si}$.

Еще через $\sim 11 \mu \mathrm{s}$ поверхность сжимается. Это приводит к уменьшению интенсивности вспышек в $\sim 2$ раза. Но процесс их образования продолжается.

Новое растяжение поверхности через $\sim 11 \mu$ s приводит к небольшому (на 20-50\%) увеличению интенсивности вспышек.

При последующих растяжениях и сжатиях поверхности число и интенсивность вспышек уменьшаются, и к $\sim 200 \mu$ s процесс появления новых вспышек заканчивается.

Таким образом, весь процесс накопления разрывов связей $\mathrm{Si}-\mathrm{O}-\mathrm{Si}$ занимает $\sim 50 \mu \mathrm{s}$. 


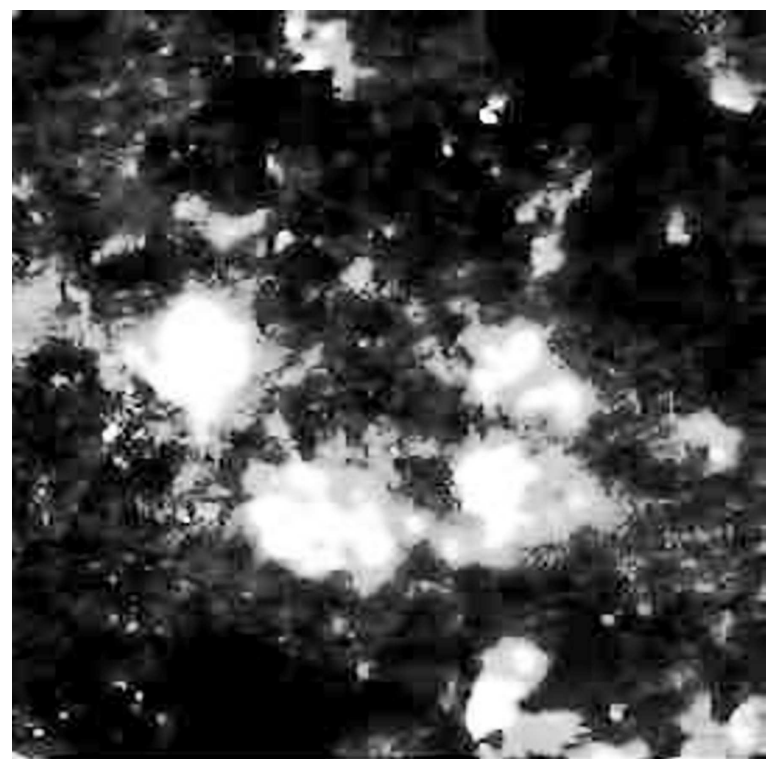

$25 \mu \mathrm{m}$

Рис. 4. Микротрещины в зерне полевого шпата, образовавшиеся после удара по нему бойком.

Рассмотрим теперь форму вспышек (рис. 3). Видно, что они состоят из нескольких (6-10) максимумов, наложенных друг на друга. Время возгорания $t_{h}$ вспышек изменяется от $\sim 2$ до $\sim 20 \mathrm{~ns}$.

Предположим, что каждый максимум соответствует рождению микротрещины, и оценим ее размеры $l$. Скорость роста микротрещин задана скоростью пробега волны деформации в граните $(\sim 1 \mathrm{~km} / \mathrm{s})$ [8-10]. Тогда за 2-20 ns трещины должны достигать размера $2-20 \mu \mathrm{m}$.

Микротрещины можно наблюдать при помощи оптического микроскопа. Для примера на рис. 4 показана фотография поверхности зерна полевого шпата на поверхности гранита после удара по нему бойком. Белые пятна - микротрещины. Их поверхности приблизительно параллельны поверхности образца. Поэтому они эффективно рассеивают свет и выглядят как белые пятна. Из приведенной выше фотографии следует, что размеры микротрещин варьируются от $\sim 1$ до $\sim 20 \mu \mathrm{m}$. Это хорошо согласуется с приведенной выше оценкой размера по временно́й зависимости FL.

Кроме того, из анализа временно́й зависимости интенсивности FL (зависимость $a$ на рис. 2) следует, что микротрещины рождаются кластерами по 4-10штук. Это заключение согласуется с результатами анализа фотографий поверхности гранита после удара. Действительно, из рассмотрения рис. 4 следует, что микротрещины образуют кластеры из нескольких микротрещин.

Таким образом, изменение разрешения установки от 10 до $2 \mathrm{~ns}$ позволило выявить следующее: то, что ранее воспринималось как отдельные микротрещины, представляет собой кластеры из них. Линейные размеры кластеров $(\sim 30-40 \mu \mathrm{m})$ на два порядка меньше размеров зерен полевого шпата. Природа кластеризации неясна. По-видимому, внутри полевого шпата содержатся сильно неупорядоченные области размерами в несколько десятков микрометров, в которых и рождаются микротрещины.

Рассмотрим теперь временну́ю зависимость деформации.

\section{4. Временна́я зависимость деформации}

Зависимость деформации поверхности от времени представляет собой интенсивную волну, на которую накладывается набор слабоинтенсивных волн растяжениясжатия поверхности (рис. 1 и 2).

Интенсивная волна начинает формироваться в момент времени $\sim 162.9 \mu \mathrm{s}$ (кривая $b$ на рис. 1$)$. Ее период $\tau_{s}$ составляет $\sim 23 \mu \mathrm{s}$, а амплитуда со временем растет.

Слабоинтенсивные волны, как уже упоминалось, появляются в момент образования первой вспышки FL. Их период составляет $0.8-1.4 \mu \mathrm{s}$ (рис. 1).

Выясним природу этих волн.

Длина волны $\lambda$ собственных колебаний образца приблизительно в 2 раза больше его размера $L=\lambda / 2$ $=S \tau_{s} / 2$. Умножая скорость пробега волн деформации $S=1 \mathrm{~km} / \mathrm{s}$ на время полупериода первой волны, мы нашли $L \approx 11 \mathrm{~mm}$, что совпадает с размерами образцов гранита. Это означает, что интенсивные колебания представляют собой собственные колебания образцов.

Точно так же, умножая скорость пробега волн деформации на время полупериодов слабоинтенсивных волн $\tau_{g} / 2$, мы получили набор величин от 0.4 до $1.4 \mathrm{~mm}$. Такие же размеры $(0.4-1.4 \mathrm{~mm})$ имеют зерна полевого шпата (см. выше). Следовательно, слабоинтенсивные колебания представляют собой собственные колебания зерен полевого шпата. Обращает на себя внимание то, что эти колебания появляются в момент возникновения первых микротрещин, т.е. уже при $t \approx 148 \mu \mathrm{s}$. Повидимому, именно образование микротрещин вызывает собственные колебания зерен полевого шпата.

Таким образом, удар по поверхности образца гранита вызывает его собственные колебания. При таких колебаниях в кристаллической решетке полевого шпата образуются микротрещины. В свою очередь образование микротрещин вызывает собственные колебания зерен полевого шпата.

\section{5. Заключение}

Удар стальным бойком по поверхности гранита приводит к появлению собственных колебаний образца и формированию в нем кластеров, содержащих от четырех до десяти микротрещин. Микротрещины образуются внутри зерен полевого шпата, что вызывает появление собственных колебаний зерен. 


\section{Список литературы}

[1] G.N. Chapman, A.J. Walton. J. Appl. Phys. 54, 5961 (1983).

[2] А.Н. Стрелецкий, А.Б. Пакович, И.Ю. Бутягин. Изв. АН СССР. Сер. хим. 50, 477 (1986).

[3] Y. Kawaguchi. Phys. Rev. B 52, 9224 (1995).

[4] Y. Kawaguchi. Phys. Rev. B 54, 9721 (1996).

[5] Y. Kawaguchi. Jpn. J. Appl. Phys. 37, 1892 (1998).

[6] В.И. Веттегрень, А.Я. Башкарев, Р.И. Мамалимов, И.П. Щербаков. ФТТ 50, 29 (2008).

[7] В.И. Веттегрень, В.С. Куксенко, И.П. Щербаков. ЖТФ 81, 4, 148 (2011).

[8] В.И. Веттегрень, В.С. Куксенко, И.П. Щербаков. ФТТ 54, 1342 (2012).

[9] В.И. Веттегрень, В.С. Куксенко, Р.И. Мамалимов, И.П. Щербаков. Физика Земли 5, 58 (2012).

[10] В.И. Веттегрень, В.С. Куксенко, И.П. Щербаков. Физика Земли 4, 1 (2016).

[11] N.J. Turro. Modern molecular photochemistry. University Science Book, N.Y. (1991). 628 p. 